\title{
Harald Seidelin. Su labor en Yucatán, México.
}

\author{
Historia de la Medicina
}

Alejandro Cervera-Andrade.

Fac. de Medicina, Universidad de Yucatán, Mérida, Yucatán, México.

\section{RESUMEN.}

Al comenzar la primavera del año 1906, llegó a Mérida, Yucatán un médico danés cuyo nombre era Harald Seidelin. Con la llegada de Seidelin comienza el período más brillante de la Escuela de Medicina de Mérida, que ya en esa época contaba con maestros competentísimos como los Dres. Saturnino Guzmán Cervera, en la clínica quirúrgica, y Maximiliano Canto Méndez y Gustavo Vega y Loyo, en la clínica médica. Los diagnósticos se ratificaban o rectificaban en el anfiteatro y en el laboratorio y ya no quedaban sujetos a la maledicencia, sino que recibían el veredicto imparcial de la ciencia. Las cátedras de Química Clínica, Anatomía Patológica, y Bacteriología se hicieron prácticas. Fue también dicho sabio danés quien hizo por primera vez en Mérida, y quizás en la República Mexicana, la reacción de Wassermann en la sangre de los enfermos para comprobar el diagnóstico de la sífilis y la reacción de Widal para confirmar el microbio de la fiebre tifoidea.

* Publicación póstuma. Reproducida de Cervera-Andrade A., Apuntes históricos de la Medicina en Yucatán Cuadernos de la Facultad de Medicina No. 7, Mérida; Universidad Autónoma de Yucatán; 1990. p. 51-4.

Solicitud de sobretiros: Revista Biomédica, Av. Itzáes No. 490 x 59, C.P. 97000, Mérida, Yucatán, México. Fax. (999) 923-61-20 Aceptado para publicación 6/Septiembre/2002

Este artículo está disponible en http://www.uady.mx/ biomedic/rb021338.pdf
El Dr. Seidelin estuvo en Mérida desde 1906 hasta 1910, fecha en que renunció a las cátedras, dejando éstas en manos de sus discípulos Amado Villa en la Química Clínica, Diego Hernández Fajardo, en la Dirección de los laboratorios, Abelardo Lara Negrón en la de Bacteriología e Hircano Ayuso Oribe en la de Anatomía Patológica. El 29 de diciembre de 1911, volvió a Yucatán, comisionado por la Escuela de Medicina de Liverpool para estudiar la fiebre amarilla, en cuya labor empleó cinco meses, partiendo de Mérida, el 27 de mayo de 1912, con rumbo a Liverpool, ausentándose de Yucatán definitivamente. Trabajó después en otras regiones del globo y algunos años antes de morir tuvo la desilusión de comprobar que su paraplasma flavigenum, no era el agente productor de la fiebre amarilla. Y el paraplasma pasó a la historia. (Rev Biomed 2002; 13:221-224)

Palabras clave: Historia de la Medicina, fiebre amarilla, Yucatán México. 
A Cervera-Andrade.

\section{SUMMARY.}

Harald Seidelin. His work in Yucatan, Mexico.

Harald Seidelin, a Danish Doctor, came to Merida at the beginning of spring 1906. With the arrival of Seidelin came most outstanding period of the Merida School of Medicine, since at the time the School of Medicine had some excellet professors like Dr. Saturnino Guzman Cervera in Surgery; Maximiliano Canto Mendez and Gustavo Vega y Loyo in the clinic. The diagnoses were ratified or rectified in the ampitheatre and in the laboratory, they were not subject to slander, but received an impartial scientific verdict. The Chairs of Clinical Chemistry, Pathological Anatomy and Bacteriology became useful. Seidelin was also the first Doctor in Merida, and perhaps in the whole of Mexico, to use blood tests to confirm diagnoses; the Wasserman test for syphilis and the Widal test for the typhoid fever microbe.

Dr. Seidelin was in Merida from 1906 to 1910, on leaving he resigned the chairs, leaving them in the hands of this disciples; Amado Villa in Clinical chemistry, Diego Hernandez Fajardo in the management of the laboratories, Abelardo Lara Negron in Bacteriology and Hircano Ayuso Oribe in the Pathological Anatomy Laboratory. On December 29, 1911, he returned to Yucatan commossioned by the Liverpool School of Medicine to study yellow fever, he stayed for five months. He left Merida on May 27, 1912 for Liverpool and never returned to Yucatan. Afterwards, he worked in other countries around the world and a few years before he died, he sufferred the disappointment of proving that the paraplasma flavigenum was not the causal agent of yellow fever. The paraplasma became history.

(Rev Biomed 2002; 13:221-224)

Key words: History of medicine, yellow fever, Yucatan Mexico.

Al comenzar la primavera del año 1906 pocos días después de inaugurado el nuevo edificio del
Hospital O’Horán, llegó a Mérida un médico danés, graduado en la Universidad de Copenhague y especializado en trabajos de laboratorio, cuyo nombre era Harald Seidelin,. Era un hombre de aspecto agradable, más bien bajo que alto, de pelo rubio y ojos azules, correctamente vestido, de rostro rasurado, de modales distinguidos, hablaba el español con ese acento extraño con que los sajones hablan la lengua de Castilla, parco en su charla, comedido en sus palabras y correctísimo en todo y por todo, pues era incapaz de hablar mal de nadie, ni de pronunciar una mentira. Esta descripción hecha por uno de sus alumnos, el Dr. Diego Hernández Fajardo (mi maestro de bacteriología), nos pinta de una pincelada al retrato del Dr. Seidelin, uno de los maestros más insignes que ha tenido la Escuela de Medicina de Yucatán.

¿Cómo y por qué aquel investigador infatigable abandonó las brumosas playas del Seeland acariciadas por la brisa del mar Báltico, para venir a estas inhospitalarias tierras eternamente amenazadas por la fiebre amarilla? No fue el espíritu de aventura sino la pasión por la investigación científica, como pudo comprobarse después. Acababa de llegar a México, cuando el gobernador de Yucatán, don Olegario Molina, fue presentado a él por el Dr. Ramón Albert Pacheco. El gobernador Molina había pensado enviar algunos estudiantes a Europa para especializarse en Bacteriología y Anatomía Patológica, con el fin de establecer en la Escuela de Mérida las cátedras correspondientes en debida forma y hacer la enseñanza práctica y efectiva. El Dr. Albert, conocedor de estos planes, sugirió al Sr. Molina la conveniencia de nombrar al Dr. Seidelin para esas cátedras, habiéndose puesto de acuerdo en esa entrevista. Así fue como nuestra Escuela tuvo la gran oportunidad de encauzar su programa educativo sobre bases sólidas, haciendo la enseñanza efectiva con trabajos prácticos en el anfiteatro y en el laboratorio.

Con la llegada de Seidelin comienza el período más brillante de la Escuela de Medicina de Mérida, que ya en esa época contaba con maestros

\section{Revista Biomédica}


Harald Seidelin en Yucatán, México.

competentísimos como los Dres. Saturnino Guzmán Cervera, en la clínica quirúrgica, y Maximiliano Canto Méndez y Gustavo Vega y Loyo, en la clínica médica. Los diagnósticos se ratificaban o rectificaban en el anfiteatro y en el laboratorio y ya no quedaban sujetos a la maledicencia sino que recibían el veredicto imparcial de la ciencia. Las cátedras de Química Clínica, Anatomía Patológica, y Bacteriología, se hicieron prácticas; en los laboratorios comenzaron a hacerse, no solamente los análisis de orina sino también de materias fecales, contenido gástrico, esputos, sangre, líquido cefalo-raquídeo, exudados vaginales y secreciones nasales. El beneficio de estos laboratorios se extendió hasta a otras actividades, no ya clínicas sino de interés colectivo, como el análisis de las. aguas de los aljibes de la ciudad, para comprobar su potabilidad desde el punto de vista bacteriológico, labor en cuyo desempeño tomó parte activa el Lic. y Dr. Amado Villa, discípulo de Seidelin.

Fue también dicho sabio danés quien hizo por primera vez en Mérida, y quizás en la República Mexicana, la reacción de Wassermann en la sangre de los enfermos, para comprobar el diagnóstico de la sífilis, y la reacción de Widal para confirmar el microbio de la fiebre tifoidea. Al Dr. Seidelin se le debe también la formación de un museo de Anatomía Patológica, que ocupaba, en su época, un espacioso salón, en uno de los cuerpos de edificio situado en la parte oriente del Hospital, junto a la biblioteca del departamento de los practicantes internos. De Seidelin dicen los que fueron sus alumnos, que tenía gran afición a su trabajo y mucho gusto en enseñar; era un verdadero placer para él, ir descubriendo a los alumnos nuevos horizontes bajo el campo del microscopio, en el cual sabía encontrar una santa belleza, aún al examinar una deyección humana, lo que a cualquiera otro que no hubiera sentido esa pasión por la ciencia, le hubiera parecido una cosa asquerosa.

El Dr. Seidelin estuvo en Mérida desde 1906 hasta 1910, fecha en que renunció a las cátedras, dejando éstas en manos de sus discípulos: Amado Villa en la Química Clínica, Diego Hernández Fajardo, en la Dirección de los laboratorios, Abelardo Lara Negrón en la de Bacteriología e Hircano Ayuso Oribe en la de Anatomía Patológica.

El 29 de diciembre de 1911, volvió a Yucatán, comisionado por la Escuela de Medicina de Liverpool para estudiar la fiebre amarilla, en cuya labor empleó cinco meses, partiendo de Mérida para el puerto de Progreso, el 27 de mayo de 1912, con rumbo a Liverpool, a donde llegó el 12 de junio. Del resultado de sus investigaciones hizo un informe pormenorizado, que la Escuela de Liverpool publicó en inglés, que traducido al español por el Dr. Eduardo Urzaiz y prologado por el Dr. Hircano Ayuso, fue publicado en la ciudad de Mérida, algún tiempo después. De Seidelin dice el Dr. Ayuso en su prólogo: ". . por voluntad del Gobierno Británico vino a Yucatán a estudiar la fiebre amarilla. Desembarcó el maestro Seidelin y su bagaje eran microscopios, ultramicroscopios, libros en español, inglés, francés, alemán, danés, italiano; su ingente acervo intelectual, su habilidad manual, -nada común- en trabajos de laboratorio, su sagacidad de investigador, y su energía física puesta a prueba, que no se quebrantaba ni un solo momento, por ímproba que fuera la faena. Ya lo conocíamos. Ya antes habíamos trabajado bajo su cautelosa dirección. Fue obra del Lic. Olegario Molina instarlo a venir a Yucatán, para que rodeado de todo lo necesario, enseñase aquí cosas de laboratorio. Habiendo desarrollado el maestro ampliamente su programa, realizó, en aquella época de nuestras grandes obras materiales, un formidable progreso de orden intelectual, imprimiendo a los métodos de diagnóstico una radicalísima reforma, y por ende, orientando hacia nuevos rumbos la terapéutica. Se puso a trabajar. Hizo cúmulo de material. Tomó apuntes y más apuntes de casos clínicos, ora en la ciudad de Mérida. ora haciendo viajes a otras poblaciones del Estado. Escribía hasta cuando iba en vehículo, consignando en su carnet alguna idea que le sugería un episodio de trabajo que momentos antes había verificado en su 


\section{A Cervera-Andrade.}

laboratorio. Y para él una imperiosa necesidad de escribirlo detalle por detalle, después de observar los hechos con sus propios ojos para no saber las cosas por referencias. No terminaba de trabajar a la hora del crepúsculo. Continuaba con la luz voltáica. Paréceme ver al Dr. Seidelin examinando multitud de botellas conteniendo larvas, escribir su procedencia y consignar la cifra de ellas; datos que luego servirían para llenar el plano de la ciudad de Mérida con los signos convencionales que nos revelarían, porque no lo sabíamos, la distribución de los mosquitos en esta urbe de los Montejos. Paréceme verlo en otra fase de su trabajo, tomando, uno por uno, centenares de mosquitos; preparándolos como se confeccionaría un fragmento de órgano para análisis histológico, fijarlos, incluirlos en parafina, hacer cortes en serie con el micrótomo, colorearlos y examinarlos al microscopio. ¿Y para qué todo esto?. Para buscar el parásito de la fiebre amarilla en algún escondrijo orgánico del insecto alado y saeteador, como encontró Ross el microbio del paludismo en el tubo digestivo y en las glándulas salivales del anofelino".

Con semejante maestro, cabía sentirse orgulloso. No hemos vuelto a tener otro, desgraciadamente. En esa temporada, el Dr. Seidelin fue atacado por la fiebre amarilla, salvándose por fortuna. En dicho año de 1912 se ausentó de Yucatán definitivamente, estuvo en otras regiones del globo, en el Congo belga, en África, y nunca olvidó a sus amigos de Mérida, con quienes tenía correspondencia. El Dr. Diego Hernández conserva hasta hoy muchas cartas del inolvidable maestro que honró a nuestra Escuela. Algunos años antes de morir tuvo la desilusión de comprobar que su paraplasma flavigenum, no era el agente productor de la fiebre amarilla; y el paraplasma pasó a la historia como pasaron el bacilo de Sanarelli, la bacteria de Richardson, el bacilo de Le Dantec, el bacilo de Gibier, el micrococo de Freiré. Pero a Seidelin, como a los hombres verdaderamente sabios, lo único que le interesaba era encontrar la verdad.

\section{Revista Biomédica}

